\title{
Translating chitosan to clinical delivery of nucleic acid-based drugis
}

\section{Carla Pereira Gomes(a1), Cátia Daniela Ferreira Lopes(a2), Pedro Miguel Duarte Moreno(a3), Aida Varela-Moreira(a4), Maria José Alonso(a5) and Ana Paula Pêgo(a6)}

\author{
(a)Instituto de Engenharia Biomédica, Universidade do Porto, Rua do Campo Alegre, Portugal; \\ carla.gomes@ineb.up.pt \\ (a2)Instituto de Engenharia Biomédica, Universidade do Porto, Rua do Campo Alegre, Portugal; \\ catia.lopes@ineb.up.pt \\ (a))Instituto de Engenharia Biomédica, Universidade do Porto, Rua do Campo Alegre, Portugal; \\ pedro.moreno@ineb.up.pt \\ (a4)Instituto de Engenharia Biomédica, Universidade do Porto, Rua do Campo Alegre, Portugal; \\ aida.moreira@ineb.up.pt \\ (a)) CIMUS Research Center, School of Pharmacy, University of Santiago de Compostela, Spain; \\ mariaj.alonso@usc.es \\ (a6)Instituto de Engenharia Biomédica, Universidade do Porto, Rua do Campo Alegre, Portugal; \\ apego@ineb.up.pt
}

Originally published in MRS Bulletin, January 2014, Volume 39, Issue 1, pp. 60-70 DOI: 10.1557/mrs. 2013.314

\begin{abstract}
A number of systems based on synthetic molecules, among them cationic liposomes and poly(ethylene imine)-based polymers, have been proposed as delivery vehicles for nucleic acids. Some of these systems have even reached the market, ensuring efficient and transient transfection levels in a variety of cell types. However, toxicity issues have limited their application in vivo. In this context, chitosan, a biocompatible and biodegradable polysaccharide, has been proposed as a promising alternative for the delivery of nucleic acid-based molecules. Here we present an overview of the state of the art of chitosan-based vectors for nucleic acid delivery and the most recent data on the in vivo testing of the proposed systems. We additionally express our view on the barriers that might be hampering the translation of this knowledge into clinical practice and the challenges that need to be fulfilled for these promising vehicles to reach patients.
\end{abstract}




\section{Chitosan: Sources and properties}

Chitosan is a linear co-polymer of D-glucosamine and N -acetyl- D-glucosamine in a $\beta$-(1-4) linkage, in which glucosamine is the predominant repeating unit (Figure 1 ). The molar fraction of $\mathrm{N}$-acetylated units defines the degree of acetylation (DA) of a given chitosan, expressed in molar percentage of $\mathrm{N}$ acetylated units. Chitosan is soluble in lightly acidic aqueous solutions. At a pH lower than its pKa, ranging from $\sim 6.5$ to $\sim 7$, chitosan is a polycation, and at $\mathrm{pH} 4.0$ and below, it is completely protonated. ${ }^{1}$ The cationic character of chitosan under mildly acidic conditions and its ability to complex and condense nucleic acid-based molecules are the basis for its use as a transfection agent.

Chitosan is mostly obtained by deacetylation of chitin. The most commonly used sources of chitin are the exoskeleton of crustaceans and squids. The chitin present in squid pens is easier to deacetylate due to the absence of inter-sheet hydrogen bonding. ${ }^{2}$ To conduct the deacetylation process with chitin from crustaceans, harsher conditions need to be applied, and the resulting chitosan typically has lower molecular weight. Consequently, this has been the preferred source of chitosan for use in nucleic acid delivery, as smaller and less disperse complexes can be formed when chitosan of lower molecular weight is used. 3,4 In either case, the fact that chitosan has an animal origin has raised some concerns, as it might be a potential source of allergens. More recently, chitosan isolated from the cell walls of mushrooms has become commercially available. As compared to chitosan obtained from marine animal resources, chitosan isolated from fungi cultured under controlled growing conditions presents higher reproducibility among batches and traceability, ${ }^{5}$ which makes it of interest for application in medical and pharmaceutical products. Irrespective of the original source, chitosan of ultrapure grade can now be obtained.

In addition to its ability to condense nucleic acid-based molecules and protect them from endonuclease degradation, a particular advantage of chitosan over other polycations proposed as non-viral vectors for nucleic acids relies on its low cytotoxicity and biodegradability. Besides chemical hydrolysis, enzymes can also mediate chitosan degradation in vivo. ${ }^{6}$ Among these, lysozyme has been identifi ed as the main one being involved in this process.7,8 It can hydrolyze partially $\mathrm{N}$ acetylated chitosans, with the active site of the enzyme binding six sugar rings, being three consecutive $\mathrm{N}$-acetyl-D-glucosamine residues required for lysozyme catalytic activity.7 As a consequence, the susceptibility of chitosan to lysozyme depolymerization depends not only on the DA but also on the distribution of $\mathrm{N}$-acetylated units along the chitosan chains.

Further contributions to the fi eld are expected when enzymatic production of chitosan will become readily available. 9 This will allow precise control over the resulting chain molecular weight, DA, and the distribution of the monomer units along the polymer backbone. Consequently, nanocomplex formation reproducibility and fine-tuning of biodegradation can be achieved, ultimately affecting the overall process of cell transfection.

\section{Chitosan as a vector for nucleic acid delivery}

Gene therapy is currently considered a strategy that provides cells with the genetic information required to produce specific therapeutic proteins or increase their overall expression levels, thus correcting or modulating specific pathologies. Moreover, the concept has been expanded to include specific regulation of gene expression through the use of short oligonucleotides targeting DNA or RNA, otherwise named as antisense gene therapy or oligonucleotide gene therapy. 
Over the past several years, many attempts have been made to design non-viral vectors that could achieve the level of gene expression and specificity attained by viral vectors, while providing greater flexibility in terms of size of the transported nucleotide cargo, bypassing the immune system, and reducing safety concerns..$^{10}$ Among them, chitosan-based carriers have gained a great deal of attention for delivery of plasmid DNA (pDNA), small interference RNA (siRNA), and single-stranded oligonucleotides ( $\mathrm{sSON}$ ) (Figure 2). In the following sections, we present the state of the art of chitosan-based nanocarriers, focusing on their ability to deliver different types of nucleic acids.

\section{Plasmid DNA}

At the molecular level, pDNA can be considered to be a pro-drug that, upon cellular internalization and nuclear entry, leads to the biosynthesis of a therapeutic protein ${ }^{11}$ (Figure 2a). In addition to disease treatment, plasmids can be used as DNA vaccines for genetic immunization. DNA vaccines function through induction of immune response by introducing gene encoding antigens for specific pathogens. ${ }^{12}$ pDNA is a double-stranded DNA molecule (1-200,000 base pairs) that can occur in three topological forms: the compact supercoiled form, the open circular form, and the linearized form.

Supercoiling arises from inherent properties of the DNA double helix to twist (turn) and writhe (turn over itself) and allows formation of a more compact molecule with implications for complex formation and transfection capabilities, also dependent on the type of vector used. ${ }^{13}$ The US Food and Drug Administration (FDA) guidelines require the majority of pDNA (>80\%) to be in its supercoiled form for application in pDNA vaccines for infectious disease indications. ${ }^{14}$

There are a large number of reports describing the potential of chitosan and its derivatives for pDNA delivery. ${ }^{15}$ Both chitosan-pDNA complexes ${ }^{16}$ and chitosan-based nanocarriers prepared by ionic gelation ${ }^{17,18}$ have been described for pDNA transfection. Overall, results revealed that transfection efficiency of chitosan-based delivery vehicles is dependent on several formulation parameters, such as chitosan molecular weight, DA, and stoichiometry ( $/ \mathrm{P}$ ratio, moles of positive charges from amino groups to moles of negative charges from phosphate groups), among others. ${ }^{19}$ Therefore, these parameters should be carefully considered and optimized when designing a pDNA delivery system. An in-depth review describing factors affecting pDNA delivery mediated by chitosan has been recently published. ${ }^{20}$

Although chitosan has been proposed as an alternative to other non-viral vectors such as cationic liposomes or poly(ethylene imine) (PEI), it generally presents lower transfection efficiencies. ${ }^{21}$ This difference could be attributed to its limited solubility at physiological $\mathrm{pH}$ as well as to its inefficient cellular uptake, endolysosome escape, and polyplex dissociation (see Figure 2a). Consequently, several efforts are being made toward improving chitosan transfection efficiency by introducing different types of chemical modifi cations into the polymer backbone.

One common approach to enhance transfection efficiency is by improving chitosan solubility under physiological conditions. Chitosan grafted with PEI led to increased solubility, as well as improved transfection efficiency in relation to PEI alone.22 Another strategy relies on the grafting of the poly(ethylene glycol) chain (PEGylation) to chitosan, which improves polymer solubility, yielding nanostructures that are more stable in the blood stream (extending their circulation time) and mediating transfection more efficiently.23,24 The quaternization of chitosan by methylation of 
primary amine groups was also found to improve chitosan solubility and polyplex stability in physiological conditions. ${ }^{25}$

In order to overcome the endosomal barrier (see Figure 2a), conjugation of imidazole to chitosan has been explored to improve chitosan buffering capacity and endosomal escape. ${ }^{26,27}$ The introduction of hydrophobic moieties into the polymer backbone also led to more efficient endosomal escape ${ }^{28}$ along with improvement of pDNA condensation capacity due to enhanced interaction between tethered hydrophobic domains and nucleic acids. Thiolation of chitosan also resulted in improvement of pDNA protection against degradation and formation of more stable complexes via establishment of disulfide bonds between chitosan chains. Additionally, in the reductive environment of the cytoplasm, there is an enhanced dissociation of pDNA from the polymer resulting in enhanced transgene expression. ${ }^{29,30}$ Finally, an amphiphilic modification of chitosan has also been attempted. Hydrophobic modification of chitosan with linoleic acid led to improved endonuclease protection ability, promoting cell binding and enhanced pDNA dissociation. Contrarily, introduction of poly(beta-malic acid) via ester bonds led to enhanced water solubility, minimized nonspecific protein adsorption, and facilitated pDNA unloading, resulting in an overall improved transfection efficiency. ${ }^{31}$

As an alternative to chitosan backbone modification, the preparation of ionically cross-linked chitosan-TPP (tripolyphosphate) nanoparticles was also proposed. ${ }^{22}$ Such systems were found to improve stability, achieving comparable gene expression levels to other efficient transfection agents. A more advanced system combines chitosan, TPP, and an additional poly/oligosaccharide such as hyaluronic acid 33 or beta-cyclodextrins. 34

While non-viral vectors can associate with most cell types via nonspecific binding to the cell surface, specific targeting strategies based on receptor-ligand interactions are preferable to prevent widespread delivery and off-target effects. The incorporation of targeting moieties into the chitosan nanoparticles was found to modify the particle uptake, with the ligand/ receptor interaction governing the internalization pathway and the subsequent intracellular trafficking. ${ }^{29,35,36}$

\section{Small interfering RNA}

siRNAs are short, usually 19-21 base pair double-stranded synthetic RNA molecules, which elicit the degradation of messenger RNA (mRNA), thereby achieving down-regulation of a target gene through the mechanism of RNA interference (Figure $2 \mathrm{~b}$ ). 37

Due to its chemical nature, siRNA is highly sensitive to degradation by nucleases and unable to cross cellular membranes. Being much smaller than pDNA, siRNA has far less charge

density, possessing an inherently different structure and topology. These differences underlie the specificity of certain synthetic vectors in achieving efficient delivery with only one type of nucleic acid molecule. Chitosan-based vectors follow this rule, hence chemical and physical parameters need to be specifically optimized for siRNA delivery.

To the best of our knowledge, the first report on the use of chitosan-based nanoparticles for siRNA delivery was published in 2006.38 This study explored different methods of complexation (simple coacervation, ionic gelation, and adsorption to chitosan-TPP nanoparticles prepared by ionic gelation) using high molecular weight chitosans (110-470 kDa). The results showed that the 
molecular weight did not significantly influence transfection efficiency, although smaller particles were formed with the lowest molecular weight chitosan. The method of siRNA association, in turn, was relevant for transfection efficiency, with entrapment by ionic gelation being the most effective.

Recent reports highlight the effect of chitosan molecular weight on its interaction with siRNA and the transfection efficiency of the resulting complexes. However, the results are not definite yet. Some authors indicated that low molecular weight chitosan is not able to stably interact with siRNA merely because of insufficient electrostatic interactions between the two oppositely charged molecules. This effect was observed when $10 \mathrm{kDa}$ chitosan (5\% DA) 39 was compared to that of $35 \mathrm{kDa}$ (fully deacetylated). $4^{\circ}$ In contrast, another paper showed that effi cient silencing could be achieved with a chitosan of $12 \mathrm{kDa}(8 \% \mathrm{DA}) .4^{1}$

Overall, the conclusion at this point could be that increasing polymer molecular weight might not translate into further increases in performance.40,42 This could be explained by a productive interaction threshold between siRNA and the polymer chains, leading to sufficient condensation and intracellular dissociation capacity of the complexes. The previously mentioned examples also reveal that low DAs favor the interaction with siRNA and the overall vector performance. The use of chitosan with low DA is particularly crucial when preparing nanoparticles using the ionic complexation technique. In contrast, when using the ionic gelation technique, siRNA molecules, besides establishing possible ionic interactions with chitosan, are physically entrapped during the particle formation process. 32,43

A myriad of modifications in the polymer backbone, aimed at improving nanoparticle formation with siRNAs, have been explored. Similar to pDNA delivery, chitosan quaternization 44 and chitosan thiolation 45 have also been investigated. Hydrophobic modification of chitosan with tocopheryl (vitamin E) has also been achieved. ${ }^{46}$ Other possible modifications include glycolchitosan, PEGylated chitosan, and guanidinylated chitosan, which have basically conferred improved stability, solubility, and cellular uptake resulting in enhanced transfection capabilities. ${ }^{47}$ Another alternative for efficient encapsulation of siRNA combines PEGylated chitosan with hyaluronic acid and the process of nanoparticle formation induced by ionic gelation using TPP. 48

\section{Single-stranded oligonucleotides}

The therapeutic potential of single-stranded ONs (ssONs) was discovered in 1978, when Zamecnik and Stephenson reported that a DNA oligonucleotide complementary to the target RNA was able to inhibit virus replication in cell culture. 49 Soon after, the idea of achieving generalized blocking of RNA function through hybridization of ssONs with the RNA started to develop and with it the fi eld of antisense oligonucleotides (AON). As with siRNAs, these molecules can be easily degraded and have difficulty entering cells. Attempts have been made to increase their stability by chemical modification and to maintain their effectiveness upon in vivo administration; however, the high amounts of ssONs needed to achieve a good response and the lack of specific cell targeting may raise some toxicity issues. $5^{\circ}$ Thus, the development of appropriate delivery vectors is also critical in this context (Figure 2c). As in the case of siRNA, the small size and low charge density of the molecule poses a problem for complexation. Additionally, its single-stranded character confers a slight apolar characteristic to the molecule due to exposure of aromatic nitrogenous bases. 
Although the number of reports on chitosan-based vectors for ssON delivery is still low, there are some approaches that have led to promising data. Chitosan nanocomplexes showed transfection activity in a model of intranasal application, even though very high amounts ( $100 \mu \mathrm{g}$ ) were needed to achieve a response..$^{51}$ In another example, complexes of ssON with a galactose-modified chitosan resulted in an improved in vitro transfection efficiency as compared to the parent chitosan complexes. ${ }^{2}$ Moreover, in vivo galactosylation of chitosan was found to vectorize high amounts of AON to specific liver cells, which was seen as the major event leading to the increased efficiency of this vector.

The combination of chitosan with alginate for complexation of AON either by a lyophilization 53 or a pre-gelling method 54 has also led to interesting results. Indeed, chitosan-alginate nanoparticles prepared by lyophilization showed a capacity to transfect skin cells in vivo in an excisional wound model. Those prepared according to the pre-gelling method were found to control the AON release over a 50 -hour period 55 and to transfect a human breast cancer cell line. ${ }^{5} 6$

The delivery of AON from nanoparticles made by ionic gelation has also been reported in few studies. ${ }^{57} \mathrm{~A}$ relevant example is the one showing that chitosan nanoparticles are useful carriers of AON for delivery into rat skin cells, ${ }^{8}$ with the authors suggesting the potential of this approach for topical application on human skin. More recently, the use of thiolated chitosan in order to facilitate the dissociation of the AON from the complex was also explored.59

Overall, the information reported so far does not yet offer a comprehensive view of the most favorable properties for ssON delivery by chitosan. Considering the enormous potential for ssONbased therapeutics, a more detailed view on the use of chitosan with ssON is warranted.

\section{In vivo application of chitosan as a vector for nucleic acid delivery}

Since initial proposals of chitosan as a nucleic acid delivery system, chitosan and its derivatives have been widely tested as nucleic acid carriers in animal models. The majority of the reported in vivo studies focus on the use of reporter gene models in order to evaluate biodistribution and transfection levels mediated by chitosan-pDNA complexes ${ }^{20}$ Following these pioneering studies, there has been an increasing number of reports evaluating the efficacy of chitosan as a delivery carrier of therapeutic genes, namely in the fields of cancer, infections, and inflammatory diseases (Table I).

Due to their mucoadhesive properties, chitosan-based nanoparticles have been applied in the development of strategies to treat diseases that affect mucosal surfaces, such as the gastrointestinal tract, lung, and eye. Kai and Ochiya reported successful oral delivery of the $\beta$-galactosidase reporter gene mediated by chitosan alone or $\mathrm{N}$-acetylated to the intestine. ${ }^{60}$ Others have reported similar findings in the gastric and intestinal mucosa. pDNA-loaded chitosan-based nanoparticles have also been explored in the fi eld of respiratory diseases. An example is the work of Jiang et al., in which it was shown that aerosol delivery of pDNA producing small hairpin RNA, complexed to folatechitosan-graft-PEl, specifically silenced the isoform 1 of the protein kinase B (Akt1) in lung tumor cells, resulting in lung tumorogenesis suppression. ${ }^{61}$

Hyaluronic-chitosan nanoparticles made by ionic gelation have also been proposed for the delivery of nucleic acids to the ocular mucosa, which is a thin, continuous mucous membrane layer that lines the inner surface of the eyelids and eye surface. ${ }^{62,63}$ In this case, the mucoadhesive properties of both 
polymers were combined with the $\mathrm{CD}_{44}$ targeting ability of hyaluronic acid, rendering the system very efficient for transfection of both the corneal epithelium and conjunctiva, ocular tissues that express this receptor.

Another field of application has been mucosal administration of vaccines. For example, Roy et al. reported that oral immunization with pDNA vaccine-loaded chitosan nanoparticles led to successful immunological protection in a murine peanut allergy model. ${ }^{64}$ Another pDNA vaccine encoding for the dense granule protein 1 (GRA1) has been proposed, intended to prevent Toxoplasma gondii infection. A significant immune response against the encoded protein was observed after gastric administration of chitosan nanoparticles containing GRA1 pDNA to mice. ${ }^{65}$ Nanovaccines have also been designed for intranasal administration. For example, a pDNA-loaded chitosan nanoparticle vaccine against the respiratory syncytial virus (RSV) infection was developed and tested in a murine model. The results showed an attenuation of pulmonary inflammation by induction of protective $T$ helper 1 (Th1) cell type ${ }^{66}$ and cytotoxic T lymphocyte responses ${ }^{67}$ in BALB/c mouse strain.

The encouraging results of chitosan in delivering pDNA molecules drove interest in it as an attractive carrier for siRNA. Compared to in vivo pDNA delivery, research on siRNA delivery mediated by chitosan-based vectors is still in its infancy, the majority of current work being basic research involving model siRNA molecules. Delivery of siRNA for therapeutic purposes has recently started to receive increasing attention, with specific emphasis in the field of infectious diseases and cancer (Table I). One example is intranasal delivery of chitosan nanoparticles loaded with siRNA targeting the viral NS1 gene that encodes for a RSV nonstructural protein sequence with an important role in the virus replication process. The results showed a significant reduction of virus concentration (titers) in the lung and decreased pulmonary inflammation associated with RSV infection. ${ }^{68,69}$ On the other hand, in the field of cancer therapy, Pille et al. reported a 90\% inhibition of tumor growth in a xenograft aggressive breast cancer model after intravenous administration of anti-Ras homologous A (Rho A) siRNA encapsulated in chitosan-coated polyisohexylcyanoacrylate nanoparticles. ${ }^{70}$

Although being reported as one of the most promising nucleic acid carriers for clinical applications, so far chitosan-based nanoparticles have only been evaluated in pre-clinical settings. Therefore, much research is needed in order to advance toward the clinical development phase. This advancement is expected to be favored by the fact that several chitosan-based products are under clinical development, among them, an adjuvant for a Norwalk virus-like particle, ${ }^{71}$ whereas others, such as for wound dressing and as a dietary supplement, are already being marketed.71-73

\title{
Translating chitosan into the clinic for nucleic acid delivery: progress and challenges
}

The use of chitosan nanocarriers for gene therapy is largely documented, and there is now a considerable body of knowledge supporting this application. Notwithstanding, there are still no reports of marketed products or current clinical trials with chitosan-based vectors for in vivo administration of nucleic acids. While trying to bring such products from bench-to-bedside, a number of requisites must be taken into account. Important issues to be tackled are inherent to the use of nucleic acids as therapeutic molecules, namely the optimization of sequences to ensure robust gene expression while evading immune system surveillance (pDNA) or to minimize off-targets and reduce toxicity effects (ssONs and siRNA), as well as to determine therapeutic dosages. On the other hand, the proposed vector needs to fulfill its role as a carrier of the therapeutic agent. Some of the

\author{
政
}


strategies being pursued to improve the efficiency of chitosan for nucleic acid delivery have been discussed in the previous sections. Most of the chitosan-related limitations are common to other vectors, as well as approaches being adopted to overcome these hurdles.

It is also important to consider that while chitosan is not currently listed as an excipient in any drug formulation approved by regulatory authorities, chitosan hydrochloride has been on the list of excipients of the European Pharmacopeia since $2002{ }^{92}$ and in the US Pharmacopeia and The National Formulary since 2011.93 Moreover, chitosan (from shrimp and Aspergillus niger origin) is "generally recognized as safe" by the FDA as a direct ingredient in foods and beverages. 94 Chitosan is also being used as a dietary supplement to reduce fat adsorption and in wound dressings, $9^{5}$ indicating that a good understanding of its topical and oral tolerance exists. In addition, there are a number of clinical trials reported by the FDA involving the use of chitosan for oral and nasal peptide/vaccine delivery where chitosan is being used as a vaccine adjuvant. In spite of this, there is still a need for standard guidelines describing the range of requirements, both for suppliers and product manufactures, of product quality and characterization methods. $9^{6}$ The American Society for Testing and Materials (ASTM) is making a concerted effort to establish standard guidelines for tissue-engineered medical products and has recently dedicated one of these documents (F2103-11) to the characterization and testing of chitosan salts as starting materials for biomedical applications. 97

One must be aware that chitosan is not a single chemical entity but varies in compositional DA and distribution of the monomer units along the polymer backbone and molecular weight, depending on the source, extraction, and preparation method.96, 98, 99 For nucleic acid delivery, the polymer molecular weight and DA are very important parameters, as they will have an impact in terms of chain flexibility and the number of positive charges per chitosan molecule. Moreover, solubility, biodegradability, aggregation properties, and immune response will be affected by physicochemical properties of chitosan as well. ${ }^{100}$ In this context, regulatory issues concerning polymer preparation and characterization methods will have to be addressed such that chitosan can successfully reach the clinic. In this respect, there are three main areas that must be dealt with: (1) polymer characterization and functionality, (2) product reproducibility between different batches, and (3) toxicology and longterm safety. ${ }^{101}$

The ASTM guideline F2103-11 suggests the use of infrared spectroscopy (IR) and nuclear magnetic resonance (NMR) to correctly identify chitosan. 97 It also establishes limits of insoluble impurities, residual protein content, inorganic matter, and presence of heavy metals in the chitosan samples. The ASTM standard F2260-03 describes the methodology for determination of chitosan DA using ${ }^{1} \mathrm{H}-N M R .{ }^{102}$ It is based on the work of Vårum et al. and is valid for DA values from $50 \%$ down to $1 \% .{ }^{103}$ For molecular weight determination, a specific ASTM standard (F2602-08E011) has been published. ${ }^{104}$ Several mobile phases are proposed for size exclusion chromatography, with many composed of not only acetic acid and sodium acetate, but also ammonium acetate. Finally, according to FDA specifi cations, the endotoxin content of chitosan samples should not exceed $5 \mathrm{EU} / \mathrm{kg}$ for nonintrathecal administration routes, in order for the material to be considered safe for biomedical applications. ${ }^{105}$

The ASTM guidelines represent a promising attempt to surpass some of the diffi culties listed previously. If properly followed, they should improve the manufacturing efficiency of chitosan-based products, with significant reduction in the cost of product development. 
Another key issue to take into consideration is chitosan biodegradability. In the literature, multiple studies regarding chitosan processed in different forms (hydrogels, scaffolds, beads, or just in solution) have asserted this material as biodegradable. Most of these studies assess biodegradation upon variation of the polymer DA, since this parameter is positively related with the rate of chitosan degradation. In spite of this, little is known about the degradation of chitosan in nanoparticle systems. ${ }^{106}$ The extrapolation to nanoparticle biodegradation is not straightforward, because when the polymer is complexed with nucleic acids, the exposure of acetylated groups may not favor the degradation

mediated by enzymes. Chellat and colleagues evaluated biodegradation of chitosan and chitosan complexed with xanthan ( $\mathrm{CH}-\mathrm{X}$ ) (an anionic polysaccharide) in degradation media simulating gastric (containing pepsin) or intestinal fluids (containing pancreatin) and found that chitosan degradation was faster than $\mathrm{CH}-\mathrm{X}$ microspheres. ${ }^{107}$ To the best of our knowledge, in vivo degradation of chitosan nanoparticles containing nucleic acids has not been disclosed in the literature. It is worthwhile mentioning that this is a common limitation for most nanoparticulate systems.

\section{Conclusions}

This review highlights some of the most promising results involving the use of chitosan as a vector for nucleic acids, including examples already in pre-clinical trials that have been fueling the interest of the research community and manufacturers into use of this biopolymer. Chitosan has advantages over other non-viral carriers in terms of its nontoxicity and biodegradability. Another interesting feature widely explored is the mucoadhesive properties of chitosan, with impact on gastrointestinal, lung, and ocular applications.

While the field of gene therapy is still addressing many of the hurdles that have been hampering the widespread translation of nucleic acid-based therapies to the clinic, there are several products in clinical trials based on both viral and non-viral vectors supporting the high potential of such therapeutic strategies. Recently, two products successfully reached the market (Glybera and Gendicine) for the treatment of lipoprotein lipase deficiency and head and neck squamous cell carcinoma, respectively. Nevertheless, attaining safe and efficient delivery of the nucleic acid of interest is at the forefront of this quest, which makes chitosan and its derivatives attractive candidates.

While a number of issues that are common to all non-viral vectors remain to be addressed, there are a number of questions that are particular to chitosan. Many of these involve standardization of production and characterization methodology. While seemingly trivial, these issues have held back manufacturers and made comparison between studies difficult at times. Addressing these issues will certainly provide the basis for a deeper understanding of the behavior of this material in different biomedical settings, of which vectorization of nucleic acids is an example with great therapeutic potential. We believe that this will make pharmaceutical companies more secure to bring chitosan into clinical trials and finally to the market.

\section{Acknowledgements}

The authors would like to acknowledge the FEDER funds through the Programa Operacional Factores de Competitividade - COMPETE and the Portuguese funds through FCT_Fundação para a Ciência e

(1) 
a Tecnologia (PTDC/CTM-NAN/115124/2009 and PEst-C/SAU/LAooo2/2011) that supported this work. C.P.G. and C.D.F.L. acknowledge FCT for their PhD scholarships (SFRH/BD/79930/2011 and SFRH/BD/77933/2011). P.M.D.M. is supported by a Marie Curie Actions grant within the framework of the European Union's Seventh Framework Program (PIEF-GA-2011-300485). The authors would like to thank A. Nunes (IBMC-INEB) for her contribution to the graphic design of Figure 2 ..

\section{REFERENCES}

1. P. Sorlier, A. Denuziere, C. Viton, A. Domard, Biomacromolecules 2, 765 (2001).

2. K. Kurita, Prog. Polym. Sci. 26, 1921 (2001).

3. M. Koping-Hoggard, K.M. Varum, M. Issa, S. Danielsen, B.E. Christensen, B.T. Stokke, P. Artursson, Gene Ther. 11, 1441 (2004).

4. M. Huang, C.W. Fong, E. Khor, L.Y. Lim, J. Controlled Release 106, 391 (2005).

5. M. Kannan, M. Nesakumari, K. Rajarathinam, A.J.A. Ranjit Singh, Adv. Biol. Res. 4, 10 (2010).

6. B. He, L. Wang, J. Wang, G. Li, S. Zhang, Biologia 64, 819 (2009).

7. K.M. Varum, M.M. Myhr, R.J.N. Hjerde, O. Smidsrod, Carbohydr. Res. 299, 99 (1997).

8. K.M. Varum, H.K. Holme, M. Izume, B.T. Stokke, O. Smidsrod, Biochim. Biophys. Acta 1291, 5 (1996).

9. L. Liu, Y. Liu, H.D. Shin, R. Chen, J. Li, G. Du, J. Chen, Appl. Microbiol. Biotechnol. 97, 6149 (2013).

10. A.P. Pêgo, H. Oliveira, P.M. Moreno, in Drug Delivery Systems: Advanced Technologies Potentially Applicable in Personalised Treatment (Springer, UK, 2013).

11. C. Uherek, W. Wels, Adv. Drug Delivery Rev. 44, 153 (2000).

12. S.A. Johnston, A.M. Talaat, M.J. McGuire, Arch. Med. Res. 33, 325 (2002).

13. K. Remaut, N.N. Sanders, F. Fayazpour, J. Demeester, S.C. De Smedt, J. Controlled Release 115, 335 (2006).

14. Food and Drug Administration, Guidance for Industry (Rockville, MD, 2007).

15. S. Mansouri, P. Lavigne, K. Corsi, M. Benderdour, E. Beaumont, J.C. Fernandes, Eur. J. Pharm. Biopharm. 57, 1 (2004).

16. K.Y. Lee, I.C. Kwon, Y.H. Kim, W.H. Jo, S.Y. Jeong, J. Controlled Release 51, 213 (1998).

17. N. Csaba, A. Sanchez, E. Fernandez-Megia, R. Novoa-Carballal, M.J. Alonso, Eur. J. Pharm. Sci. 23, S55 (2004).

18. Q. Gan, T. Wang, C. Cochrane, P. McCarron, Colloids Surf. B 44, 65 (2005).

19. S. Mao, W. Sun, T. Kissel, Adv. Drug Delivery Rev. 62, 12 (2010).

20. M.D. Buschmann, A. Merzouki, M. Lavertu, M. Thibault, M. Jean, V. Darras, Adv. Drug Delivery Rev. 65,1234 (2013).

21. H.-Q. Mao, K. Roy, V.L. Troung-Le, K.A. Janes, K.Y. Lin, Y. Wang, J.T. August, K.W. Leong, J. Controlled Release 70, 399 (2001).

22. K. Wong, G. Sun, X. Zhang, H. Dai, Y. Liu, C. He, K.W. Leong, Bioconjugate Chem. 17, 152 (2006).

23. X. Jiang, H. Dai, K.W. Leong, S.H. Goh, H.Q. Mao, Y.Y. Yang, J. Gene Med. 8, 477 (2006).

24. N. Csaba, M. Koping-Hoggard, E. Fernandez-Megia, R. Novoa-Carballal, R. Riguera, M.J. Alonso, J. Biomed.

Nanotechnol. 5, 162 (2009). 
25. V.K. Mourya, N.N. Inamdar, J. Mater. Sci.-Mater. Med. 20, 1057 (2009).

26. T.H. Kim, J.E. Ihm, Y.J. Choi, J.W. Nah, C.S. Cho, J. Controlled Release 93, 389 (2003).

27. C. Moreira, H. Oliveira, L.R. Pires, S. Simões, M.A. Barbosa, A.P. Pêgo, Acta Biomater. 5, 2995 (2009).

28. F.Q. Hu, M.D. Zhao, H. Yuan, J. You, Y.Z. Du, S. Zeng, Int. J. Pharm. 315, 158 (2006).

29. H. Oliveira, L.R. Pires, R. Fernandez, M.C.L. Martins, S. Simões, A.P. Pêgo,J. Biomed. Mater. Res. Part A 95 A, 801 (2010).

30. D. Lee, W. Zhang, S.A. Shirley, X. Kong, G.R. Hellermann, R.F. Lockey, S.S. Mohapatra, Pharm. Res. 24, 157 (2007).

31. B. Wang, C. He, C. Tang, C. Yin, Biomaterials 32, 4630 (2011).

32. N. Csaba, M. Koping-Hoggard, M.J. Alonso, Int. J. Pharm. 382, 205 (2009).

33. M. de la Fuente, B. Seijo, M.J. Alonso, Nanotechnology 19, 075105 (2008).

34. D. Teijeiro-Osorio, C. Remunan-Lopez, M.J. Alonso, Eur. J. Pharm. Biopharm. 71, 257 (2009).

35. F.C. Perez-Martinez, J. Guerra, I. Posadas, V. Cena, Pharm. Res. 28, 1843 (2011).

36. P. Chan, M. Kurisawa, J.E. Chung, Y.Y. Yang, Biomaterials 28, 540 (2007).

37. A. Fire, S. Xu, M.K. Montgomery, S.A. Kostas, S.E. Driver, C.C. Mello, Nature 391, 806 (1998).

38. H. Katas, H.O. Alpar, J. Controlled Release 115, 216 (2006).

39. X. Liu, K.A. Howard, M. Dong, M.O. Andersen, U.L. Rahbek, M.G. Johnsen, O.C. Hansen, F. Besenbacher, J. Kjems, Biomaterials 28, 1280 (2007).

40. J. Malmo, H. Sorgard, K.M. Varum, S.P. Strand, J. Controlled Release 158, 261 (2012).

41. M. Alameh, D. Dejesus, M. Jean, V. Darras, M. Thibault, M. Lavertu, M.D. Buschmann, A. Merzouki, Int. J. Nanomed. 7, 1399 (2012).

42. P. Holzerny, B. Ajdini, W. Heusermann, K. Bruno, M. Schuleit, L. Meinel, M. Keller, J. Controlled Release 157, 297 (2012).

43. T. Rojanarata, P. Opanasopit, S. Techaarpornkul, T. Ngawhirunpat, U. Ruktanonchai, Pharm. Res. 25, 2807 (2008).

44. V. Dehousse, N. Garbacki, S. Jaspart, D. Castagne, G. Piel, A. Colige, B. Evrard, Int. J. Biol. Macromol. 46, 342 (2010).

45. A.K. Varkouhi, R.J. Verheul, R.M. Schiffelers, T. Lammers, G. Storm, W.E. Hennink, Bioconjugate Chem. 21, 2339 (2010).

46. S.M. Noh, S.E. Han, G. Shim, K.E. Lee, C.W. Kim, S.S. Han, Y. Choi, Y.K. Kim, W.K. Kim, Y.K. Oh, Biomaterials 32,849 (2011).

47. H. Ragelle, G. Vandermeulen, V. Preat, J. Controlled Release 172, 207 (2013).

48. M. Ravina, E. Cubillo, D. Olmeda, R. Novoa-Carballal, E. Fernandez-Megia, R. Riguera, A. Sanchez, A. Cano, M.J. Alonso, Pharm. Res. 27, 2544 (2010).

49. P.C. Zamecnik, M.L. Stephenson, Proc. Natl. Acad. Sci. U.S.A. 75, 280 (1978).

50. E.M. Straarup, N. Fisker, M. Hedtjarn, M.W. Lindholm, C. Rosenbohm, V. Aarup, H.F. Hansen, H. Orum, J.B. Hansen, T. Koch, Nucleic Acids Res. 38, 7100 (2010).

51. S.T. Kim, C.K. Kim, Biomaterials 28, 3360 (2007).

Version: Postprint (identical content as published paper) This is a self-archived document from i3S - Instituto de Investigação e Inovação em Saúde in the University of Porto Open Repository For Open Access to more of our publications, please visit http://repositorio-aberto.up.pt/

INSTITUTO DE INVESTİGAÇÃO E INOVAÇÃO EM SAÚDE UNIVERSIDADE DO PORTO

Rua Alfredo Allen, 208 4200-135 Porto Portugal +351 220408800 info@i3s.up.pt www.i3s.up.pt 
52. S. Gao, J. Chen, L. Dong, Z. Ding, Y.H. Yang, J. Zhang, Eur. J. Pharm. Biopharm. 60, 327 (2005).

53. H.J. Hong, S.E. Jin, J.S. Park, W.S. Ahn, C.K. Kim, Biomaterials 29, 4831 (2008).

54. T. Gazori, M.R. Khoshayand, E. Azizi, P. Yazdizade, A. Nomani, I. Haririan, Carbohydr. Polym. 77, 599 (2009).

55. E. Azizi, A. Namazi, I. Haririan, S. Fouladdel, M.R. Khoshayand, P.Y. Shotorbani, A. Nomani, T. Gazori, Int. J. Nanomed. 5, 455 (2010).

56. T. Gazori, I. Haririan, S. Fouladdel, A. Namazi, A. Nomani, E. Azizi, Carbohydr. Polym. 80, 6 (2010).

57. T.H. Dung, S.R. Lee, S.D. Han, S.J. Kim, Y.M. Ju, M.S. Kim, H. Yoo, J. Nanosci. Nanotechnol. 7, 3695 (2007).

58. S. Ozbas-Turan, J. Akbuga, A.D. Sezer, Oligonucleotides 20, 147 (2010).

59. F. Talaei, E. Azizi, R. Dinarvand, F. Atyabi, Int. J. Nanomed. 6, 1963 (2011).

6o. E. Kai, T. Ochiya, Pharm. Res. 21, 838 (2004).

61. H.L. Jiang, C.X. Xu, Y.K. Kim, R. Arote, D. Jere, H.T. Lim, M.H. Cho, C.S. Cho, Biomaterials 30, 5844 (2009).

62. M. de la Fuente, B. Seijo, M.J. Alonso, Invest. Ophthalmol. Vis. Sci. 49, 2016 (2008).

63. M. de la Fuente, B. Seijo, M.J. Alonso, Gene Ther. 15, 668 (2008).

64. K. Roy, H.Q. Mao, S.K. Huang, K.W. Leong, Nat. Med. 5, 387 (1999).

65. M. Bivas-Benita, M. Laloup, S. Versteyhe, J. Dewit, J. De Braekeleer, E. Jongert, G. Borchard, Int. J. Pharm. 266, 17 (2003).

66. M. Kumar, A.K. Behera, R.F. Lockey, J. Zhang, G. Bhullar, C.P. De La Cruz, L.C. Chen, K.W. Leong, S.K. Huang, S.S. Mohapatra, Hum. Gene Ther. 13, 1415 (2002).

67. M. Iqbal, W. Lin, I. Jabbal-Gill, S.S. Davis, M.W. Steward, L. Illum, Vaccine 21, 1478 (2003).

68. W. Zhang, H. Yang, X. Kong, S. Mohapatra, H. San Juan-Vergara, G. Hellermann, S. Behera, R. Singam, R.F. Lockey, S.S. Mohapatra, Nat. Med. 11, 56 (2005).

69. X. Kong, W. Zhang, R.F. Lockey, A. Auais, G. Piedimonte, S.S. Mohapatra, Genet. Vaccines Ther. 5, 4 (2007).

70. J.Y. Pille, H. Li, E. Blot, J.R. Bertrand, L.L. Pritchard, P. Opolon, A. Maksimenko, H. Lu, J.P. Vannier, J. Soria, C. Malvy, C. Soria, Hum. Gene Ther. 17, 1019 (2006).

71. http://clinicaltrials.gov (data from September 2013).

72. M.A. Barbosa, A.P. Pêgo, I.F. Amaral, in Comprehensive Biomaterials,P. Ducheyne, K. Healy, D.E. Hutmacher, D.W. Grainger, C.J. Kirkpatrick, Eds. (Elsevier, London, UK, 2011), pp. $221-237$.

73. J. Shaji, V. Jain, S. Lodha, P.K.M. Kundnani, Int. J. Pharm. Appl. Sci. 1, 11 (2010).

74. W. Xu, Y. Shen, Z. Jiang, Y. Wang, Y. Chu, S. Xiong, Vaccine 22, 3603 (2004).

75. M. Bivas-Benita, K.E. van Meijgaarden, K.L. Franken, H.E. Junginger, G. Borchard, T.H. Ottenhoff, A. Geluk, Vaccine 22, 1609 (2004).

76. D. Raghuwanshi, V. Mishra, D. Das, K. Kaur, M.R. Suresh, Mol. Pharm. 9, 946 (2012).

77. C.R. Oliveira, C.M. Rezende, M.R. Silva, O.M. Borges, A.P. Pêgo, A.M. Goes, Sci. World J. 2012, 938457 (2012).

78. J.L. Chew, C.B. Wolfowicz, H.Q. Mao, K.W. Leong, K.Y. Chua, Vaccine 21, 2720 (2003).

79. M. Kumar, X. Kong, A.K. Behera, G.R. Hellermann, R.F. Lockey, S.S. Mohapatra, Genet. Vaccines Ther. 1, 3 (2003).

8o. G.P. Li, Z.G. Liu, B. Liao, N.S. Zhong, Cell Mol. Immunol. 6, 45 (2009). 
81. C.R. Dass, K.G. Contreras, D.E. Dunstan, P.F. Choong, Biomaterials 28, 3026 (2007).

82. M. Cheng, Q. Li, T. Wan, X. Hong, H. Chen, B. He, Z. Cheng, H. Xu, T. Ye, B. Zha, J. Wu, R. Zhou, J. Biomed. Mater. Res. Part B 99, 70 (2011).

83. Q.Q. Zhao, Y.L. Hu, Y. Zhou, N. Li, M. Han, G.P. Tang, F. Qiu, Y. Tabata, J. Q. Gao, Int. J. Nanomed. 7, 3191 (2012).

84. S. Feng, I.U. Agoulnik, A. Truong, Z. Li, C.J. Creighton, E.M. Kaftanovskaya, R. Pereira, H.D. Han, G. LopezBerestein, T. Klonisch, M.M. Ittmann, A.K. Sood, A.I. Agoulnik, Endocrinol. Relat. Cancer 17, 1021 (2010).

85. H.S. Kim, H.D. Han, G.N. Armaiz-Pena, R.L. Stone, E.J. Nam, J.W. Lee, M.M. Shahzad, A.M. Nick, S.J. Lee, J.W. Roh, M. Nishimura, L.S. Mangala, J. Bottsford-Miller, G.E. Gallick, G. Lopez-Berestein, A.K. Sood, Clin. Cancer Res. 17, 1713 (2011).

86. H.D. Han, E.M. Mora, J.W. Roh, M. Nishimura, S.J. Lee, R.L. Stone, M. Bar-Eli, G. Lopez-Berestein, A.K. Sood, Cancer Biol. Ther. 11, 839 (2011).

87. Z. Huang, L. Dong, J. Chen, F. Gao, Z. Zhang, J. Chen, J. Zhang, Life Sci. 91, 1207 (2012).

88. S.J. Lee, M.S. Huh, S.Y. Lee, S. Min, S. Lee, H. Koo, J.U. Chu, K.E. Lee, H. Jeon, Y. Choi, K. Choi, Y. Byun, S.Y. Jeong, K. Park, K. Kim, I.C. Kwon, Angew. Chem. Int. Ed. 51, 7203 (2012).

89. K. Bowman, R. Sarkar, S. Raut, K.W. Leong, J. Controlled Release 132, 252 (2008).

9o. K.A. Howard, S.R. Paludan, M.A. Behlke, F. Besenbacher, B. Deleuran, J. Kjems, Mol. Ther. 17, 162 (2009).

91. M. Jean, M. Alameh, M.D. Buschmann, A. Merzouki, Gene Ther. 18, 807 (2011).

92. Council of Europe, European Pharmacopeia (Strasbourg, 2002).

93. United States Pharmacopeia and the National Formulary, United States Pharmacopeial Convention

(Baltimore, United Book Press, 2011), vol. 29, p. 5361.

94. US Food and Drug Administration Gras Notice Inventory (consulted online 2013 :

http://www.fda.gov/Food/IngredientsPackagingLabeling/GRAS/Noticelnventory/default.htm).

95. J.S. Boateng, K.H. Matthews, H.N. Stevens, G.M. Eccleston, J. Pharm. Sci.97, 2892 (2008).

96. M.H. Struszczyk, "Global Requirements for Medical Applications of Chitin and its Derivatives," in Monograph XI (Polish Chitin Society, Poland, 2006).

97. ASTM Standard F2103, "Standard Guide for Characterization and Testing of Chitosan Salts as Starting Materials Intended for Use in Biomedical and Tissue-Engineered Medical Product Applications" (ASTM International, West Conshohocken, PA, 2011).

98. A.J. Varma, S.V. Deshpande, J.F. Kennedy, Carbohydr. Polym. 55, 77 (2004).

99. V. Bansal, P.K. Sharma, N. Sharma, O.P. Pal, R. Malviya, Adv. Biol. Res. 5, 28 (2011).

100. M.D. Buschmann, A. Merzouki, M. Lavertu, M. Thibault, M. Jean, V. Darras, Adv. Drug Delivery Rev. (2013), accepted for publication.

101. O. Skaugrud, A. Hagen, B. Borgersen, M. Dornish, Biotechnol. Genet. Eng.Rev. 16, 23 (1999).

102. ASTM Standard F2260, 2012e1, "Standard Test Method for Determining Degree of Deacetylation in Chitosan Salts by Proton Nuclear Magnetic Resonance (1H NMR) Spectroscopy" (ASTM International, West Conshohocken, PA, 2012).

103. K.M. Varum, M.W. Anthonsen, H. Grasdalen, O. Smidsrod, Carbohydr. Res. 211, 17 (1991). 
104. ASTM Standard F2602, 2008e1, "Standard Test Method for Determining the Molar Mass of Chitosan and Chitosan Salts by Size Exclusion Chromatography with Multi angle Light Scattering Detection (SEC MALS)" (ASTM International, West Conshohocken, PA, 2008).

105. US Food and Drug Administration, "Guidance for Industry - Pyrogen and Endotoxins Testing" (2012); www.fda.gov/downloads/Drugs/GuidanceComplianceRegulatoryInformation/Guidances/UCM310098.pdf .

106. L.R. Pires, H. Oliveira, C.C. Barrias, P. Sampaio, A.J. Pereira, H. Maiato, S. Simoes, A.P. Pêgo, Nanomedicine 6, 1499 (2011).

107. F. Chellat, M. Tabrizian, S. Dumitriu, E. Chornet, C.H. Rivard, L. Yahia, J. Biomed. Mater. Res. 53, 592 (2000).laboratory animals, V. Reinhardt and A. Reinhardt, Editors. 2002, Animal Welfare Institute. p. 56-64. 


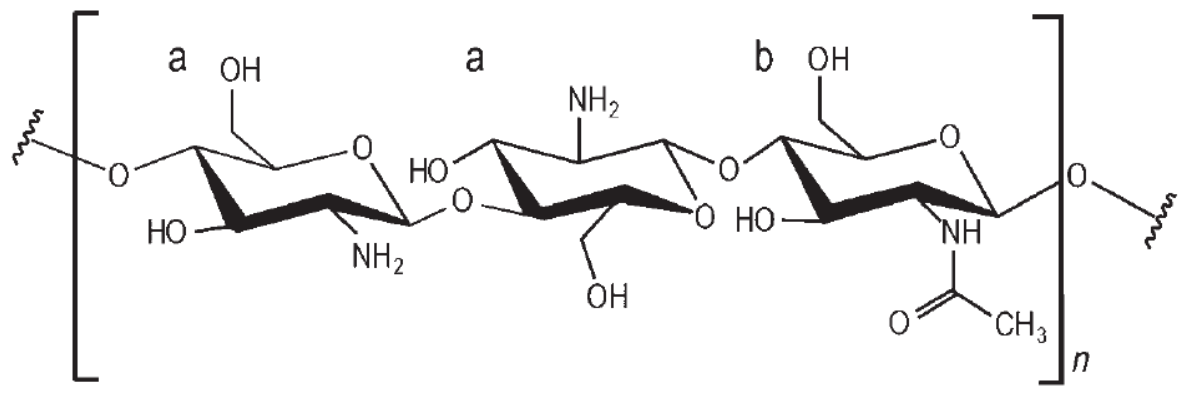

Figure 1. Chemical structure of partially deacetylated chitosan. a: D-glucosamine; b: N -acetyl Dglucosamine. Note: $n$, repetition unit.
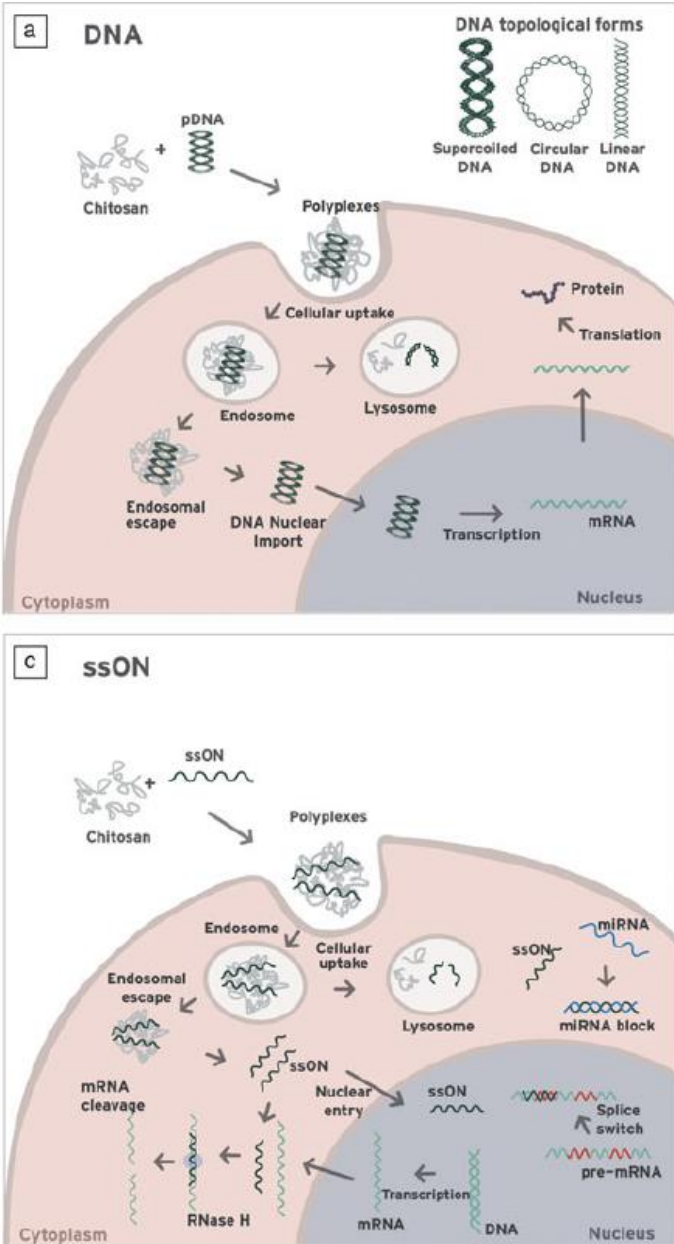

b SIRNA

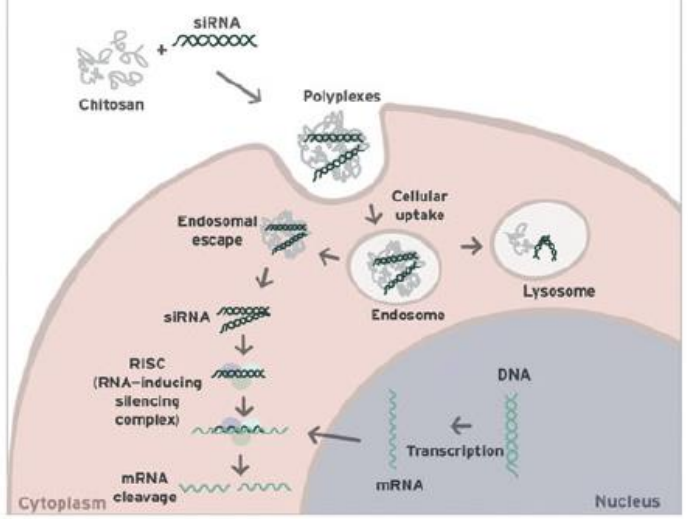

Figure 2. Schematic representation of the internalization of chitosan-nucleic acid nanoparticles and mechanisms of action of the different nucleic acids commonly used in gene therapy. After internalization, nanoparticles are trafficked along the endosomal network. Endosomes can mature into lysosomes via luminal acidification and recruitment of degradative enzymes, which target the vesicle contents for degradation. In order to access cytoplasmic or nuclear targets, nanoparticles must be capable of escaping from the endolysosomal pathway and make the nucleic acid of interest available. The three schemes present the mechanism of action of (a) plasmid DNA (pDNA) double-stranded DNA, (b) small interference RNA (siRNA)short, double-stranded, synthetic RNA, and (c) single-stranded oligonucleotides (ssONs). Note: mRNA, messenger RNA; RNase $\mathrm{H}$, endoribonuclease $\mathrm{H}$; miRNA, microRNA. 


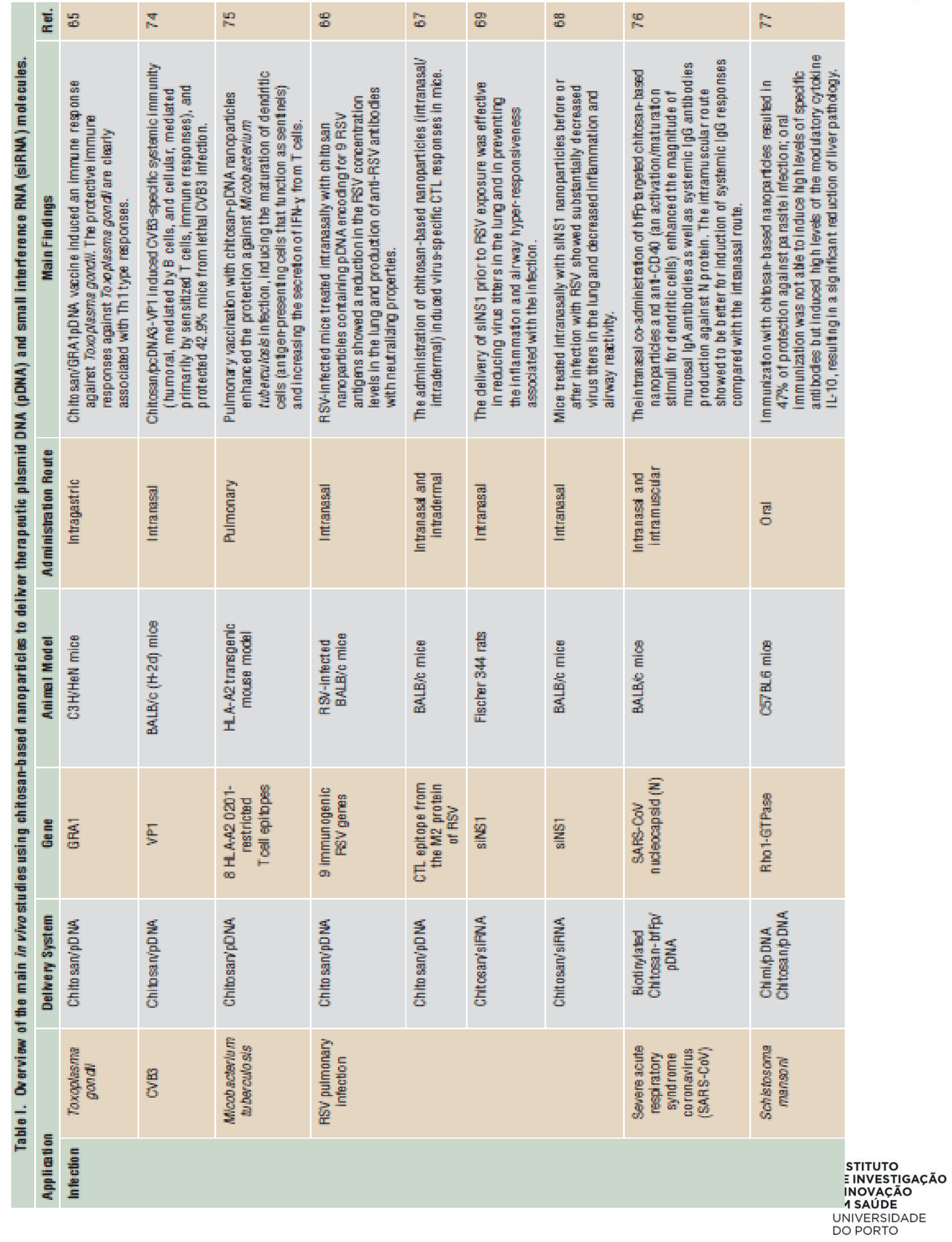




\begin{tabular}{|c|c|c|c|c|c|c|c|c|c|c|}
\hline ष्ठ & $\stackrel{\infty}{\sim}$ & 2 & ๑ & $\bar{\infty}$ & $\approx$ & ळ & $\bar{\Phi}$ & ळ & ळ & 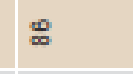 \\
\hline 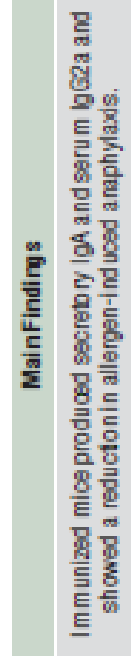 & 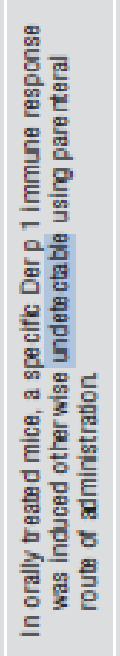 & 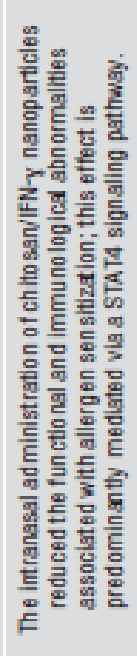 & 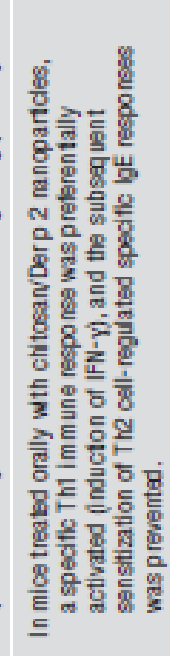 & 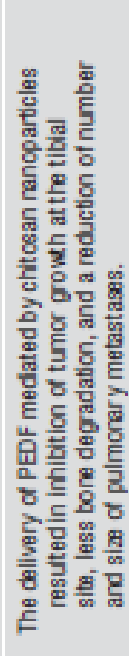 & 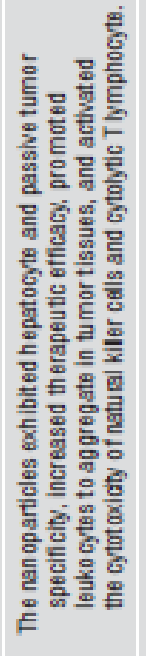 & 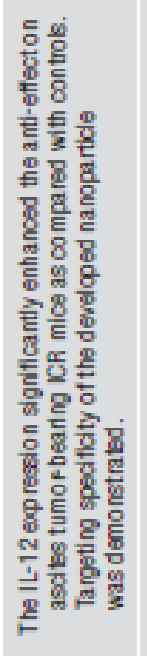 & 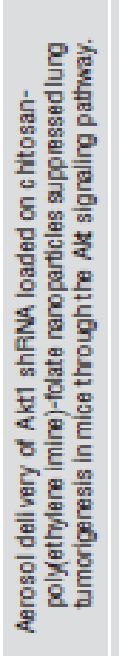 & 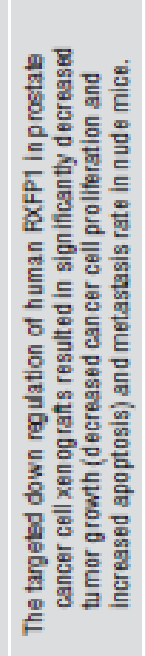 & 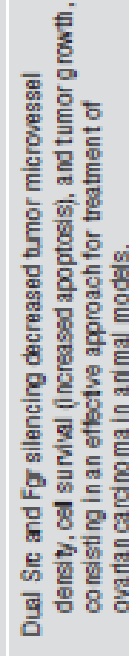 & 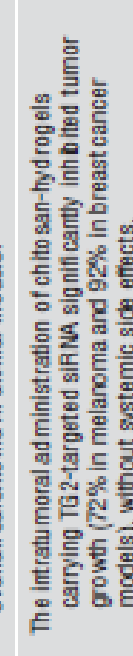 \\
\hline 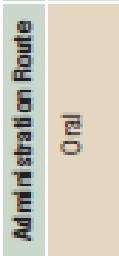 & ल्5 & 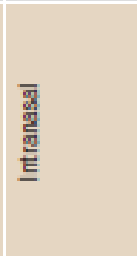 & 흥 & 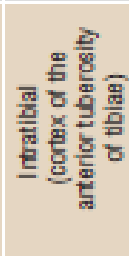 & 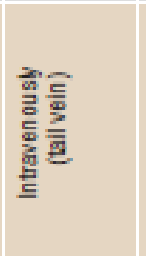 & 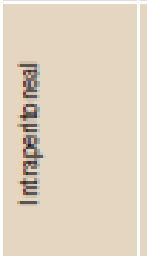 & 要 & 莺 & 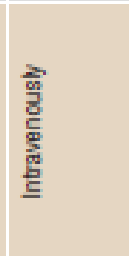 & 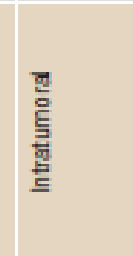 \\
\hline 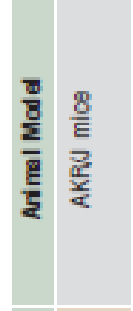 & 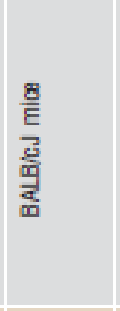 & 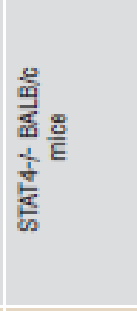 & 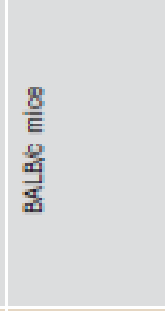 & 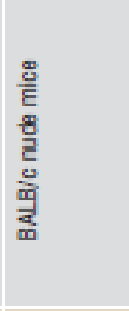 & 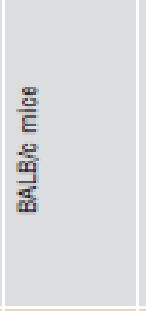 & 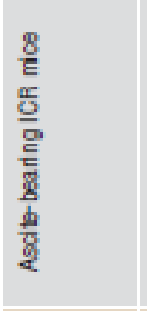 & 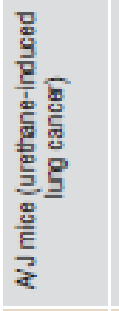 & 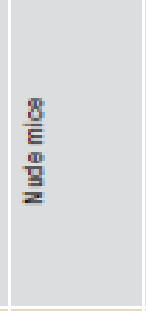 & 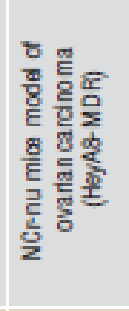 & 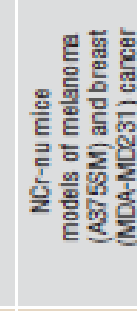 \\
\hline$\frac{\mathrm{g}}{\mathrm{g}} \frac{\mathrm{g}}{\frac{1}{\alpha}}$ & 产 & $\underline{\underline{\underline{k}}}$ & $\frac{a}{\bar{a}}$ & 岩 & 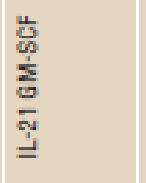 & $\stackrel{\frac{N}{\Xi}}{=}$ & $\bar{z}$ & $\frac{\bar{x}}{\frac{5}{2}}$ & 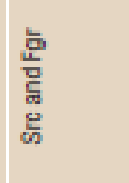 & 。ّ \\
\hline 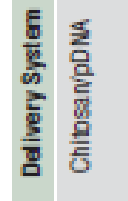 & 总 & 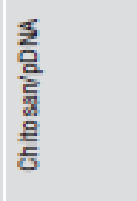 & 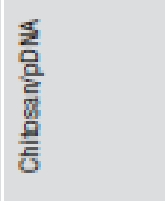 & 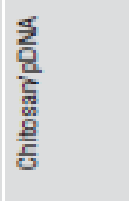 & 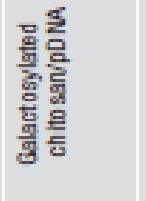 & 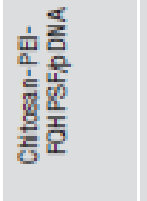 & 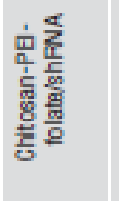 & 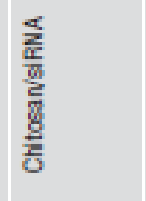 & 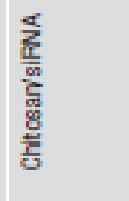 & 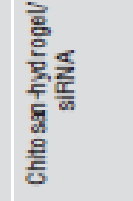 \\
\hline 它产 & 㺃 & 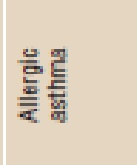 & 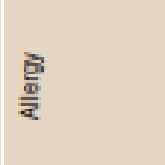 & 惹 & 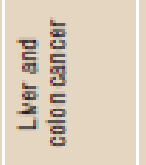 & 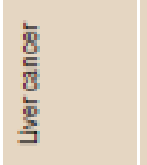 & 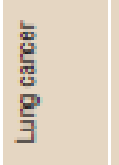 & 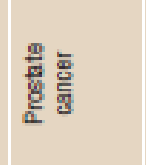 & 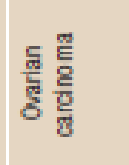 & 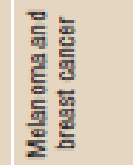 \\
\hline 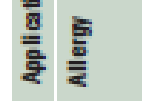 & & & & & & & & & & \\
\hline
\end{tabular}

JEINVESTIGAÇÃo EINOVAÇÃO 


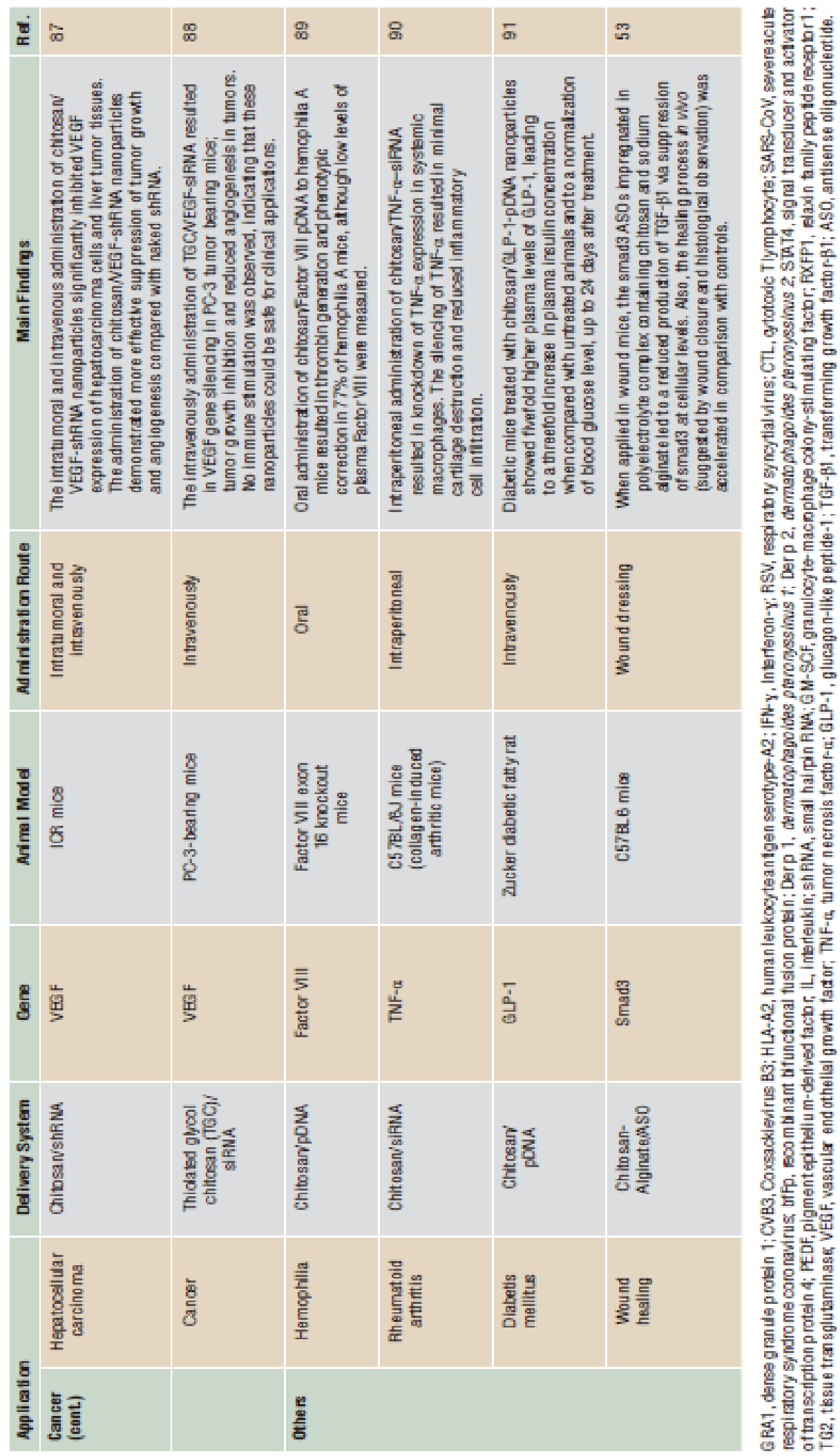

INSTITUTO

DE INVESTIGAÇÃO

E INOVAÇÃO

EM SAÚDE

UNIVERSIDADE

DO PORTO

Rua Alfredo Allen, 208 4200-135 Porto Portugal

+351 220408800

info@i3s.up.pt

www.i3s.up.pt 
Glossary

Alginate: Anionic polysaccharide present in the cell wall of brown algae.

Chitin: A high molecular weight, crystalline polysaccharide, theoretically composed entirely of Nacetylglucosamine units; it is the main component of the cell walls of fungi, the exoskeletons of arthropods such as crustaceans (e.g., crabs, lobsters, and shrimps) and insects, as well as it is present in the endoskeleton of cephalopods, including squid and octopuses.

Coacervation: The process that results in the aggregation of molecules or formation of colloidal particles under the action of electrostatic attractive forces.

Ionic gelation: The process of formation of particles driven by the reticulation (gelation) of a polymer induced by small charged molecules.

Endonuclease: Phosphodiesterase that cleaves bonds within a polynucleotide chain.

Endotoxin: Toxin present inside a bacterial cell that is released when it disintegrates; consists of lipopolysaccharide and lipoprotein complexes.

Intrathecal administration: Administration of a therapeutic agent into the subarachnoid space, which contains the cerebrospinal fl vid, in the spinal cord.

pKa: Decimal logarithm of the acid dissociation constant.

Polyplex: Complex between the cationic polymer and anionic nucleic acid.

Pro-drug: Therapeutic agent administered in an inactive form that must undergo a chemical or biological conversion before becoming an active agent.

Transfection: the process of deliberately introducing nucleic acids into cells. 